\title{
Estratégias publicitárias e produção de sentido: entre os multimeios e 0 cross media
}

João Batista Simon Ciaco

- Doutorando pelo programa de Comunicação e Semiótica na Pontifícia Universidade Católica de São Paulo (PUC-SP)

- Mestre em Administração de Empresas pela Fundação Getulio Vargas (FGV-SP), desde 2000

- Especialista, desde 1995, em Marketing pela Universidade Federal do Rio Grande do Sul (UFRGS)

- Graduado em Administração Pública pela Fundação Getulio Vargas (FGV-SP), em 1988, e em Engenharia Civil pelo Instituto Mauá de Tecnologia, em 1984

- Diretor de publicidade e marketing de relacionamento da Fiat Automóveis para o Brasil e América Latina e Presidente do Comitê de Melhores Práticas em Branding da Associação Brasileira de Anunciantes (ABA)

- Tem experiência na área de Administração, com ênfase em Administração de Empresas. Atua principalmente nos seguintes temas: Comunicação, Consumo, Discurso, Marketing, Publicidade e Semiótica

-jciaco@uol.com.br 
Resumo

A comunicação publicitária tem experimentado, nos últimos anos, uma estratégia bastante diversa da iniciativa dominante das últimas décadas: a de abolir conceito único de comunicação, replicado nas várias mídias segundo suas especificidades (estratégia multimeios), para o desenvolvimento de conceitos próprios e exclusivos para cada um dos meios e segmentos de consumidores, em estratégia fragmentada denominada cross media. Este trabalho visa analisar, sob as disposições teóricas da semiótica discursiva, as duas estratégias de comunicação publicitária nas suas relações com a produção de sentido, possibilitando assim iluminar conceitos e processos mercadológicos de marca, branding e segmentação de mercado, por olhares outros que vão além dos usualmente empregados nos departamentos de marketing e em suas agências de publicidade.

PALAVRAS-CHAVE: MULTIMEIOS • CROSS MEDIA • SEMIÓTICA • BRANDING • SEGMENTAÇÃO • EXPERIÊNCIA

\section{Abstract}

In recent years advertising has experienced a strategy that is very distinct from the dominant initiative of the last decades: the elimination of the unique communication concept, replicated in all of the media according with their specificities (multimedia strategy), in order to develop own concepts dedicated exclusively to each medium and consumer segment, in a fragmented strategy called cross media. This paper aims to analyze, under the discursive semiotics theory, both of the advertising strategies in their relationship with the production of meaning, attempting to illuminate marketing processes such as brand, branding and market segmentation, from perspectives beyond those usually used in marketing departments and their advertising agencies.

KEYWORDS: MULTIMEDIA • CROSS MEDIA • SEMIOTICS • BRANDING • SEGMENTATION • EXPERIENCE

Resumen

La comunicación publicitaria atravesó, en los últimos años, una estrategia bastante diversa de la iniciativa dominante de las últimas décadas: la de abolir un concepto único de comunicación, replicado en los varios medios según sus especificidades (estrategia multimedios) para el desarrollo de conceptos propios y exclusivos para cada uno de los medios y segmentos de consumidores, en una estrategia fragmentada denominada cross media. El objetivo de este trabajo es analizar, desde la óptica teórica de la semiótica discursiva, las dos estrategias de comunicación publicitaria en sus relaciones con la producción de sentido, lo que hace posible iluminar conceptos y procesos mercadotécnicos de marca, branding y segmentación de mercado, por medio de otras miradas que van más allá de las normalmente empleadas en los departamentos de marketing y en sus agencias de publicidad.

PALABRAS CLAVE: MULTIMEDIOS; CROSS MEDIA; SEMIÓTICA; BRANDING; SEGMENTACIÓN; EXPERIENCIA 
Im lagarto gigante invade a cidade nos outdoors espalhados pelas vias principais, nas revistas, jornais e nos comerciais de TV. Um site convida os internautas a responderem perguntas sobre algumas de suas preferências e, com isso, editar um filme on-line dirigido e produzido respectivamente pelos cineastas Rodrigo e Fernando Meirelles. Dois jovens irmãos italianos, Lucca e Sophia, povoam os sites de relacionamento com posts que os ajudem a encontrar Una Passione, uma velha escultura feita por seu avô no Brasil há algumas décadas - e com isso reconstituir um pouco da sua história de família numa busca pelo país de norte a sul, num jogo virtual que mobilizou quase uma centena de milhares de jovens. Um carro é exposto para demonstração numa plataforma, nos aeroportos brasileiros, e logo atrás uma grande tela mostra o lagarto gigante, aos moldes do apresentado na mídia, que interage com aqueles que tentam conhecer e experimentar o carro. Gigantografias do grande lagarto são coladas nas laterais de prédios nas grandes cidades. A tela do cinema convida os expectadores a votarem, por meio do celular, nas cenas que gostariam de ver em um filme interativo que se construía imediatamente após os votos da platéia. Esta foi a estratégia publicitária de lançamento do Fiat Idea Adventure, no segundo semestre de 2007.

O que caracteriza esse tipo de comunicação, além da sua grande abrangência, é a existência de peças publicitárias específicas para cada um dos meios utilizados, ou seja, recorre-se a um tipo específico de criação para a TV, outro para a

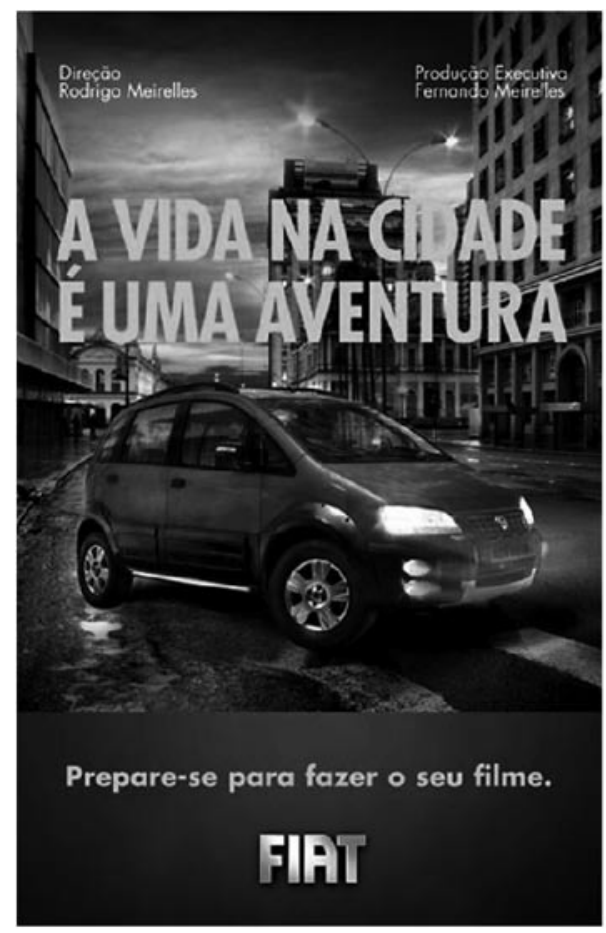

Internet e Cinema

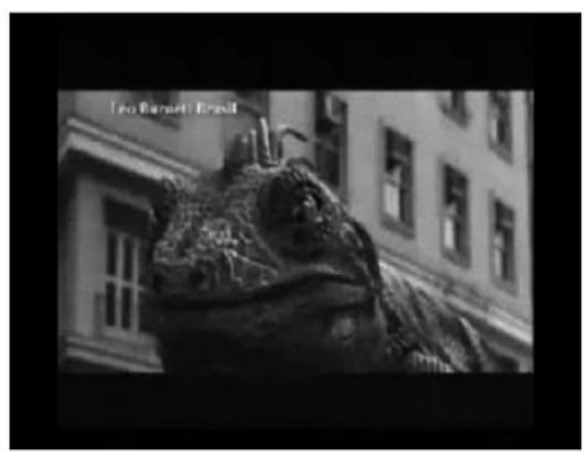

Televisão

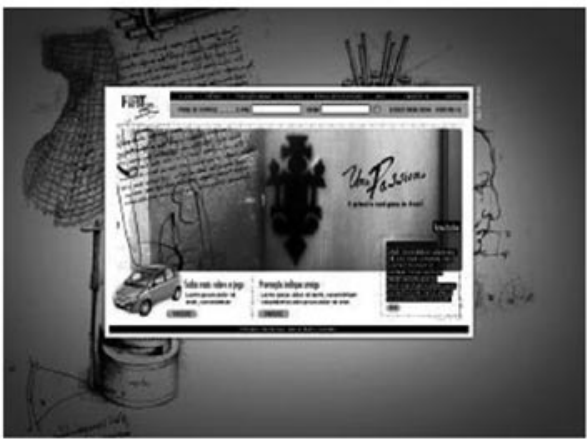

Markentig de Relacionamento 
internet, outro para o ponto de vendas e assim sucessivamente. Desta maneira, é o conjunto de todas essas peças criativas, na sua totalidade, que vai construir o sentido maior da comunicação que se deseja estabelecer. Textos inter e intrarreferenciais, é verdade, mas que guardam especificidades significativas e, mais exatamente, estratégias comunicativas muito particulares, vinculadas a cada uma das iniciativas publicitárias isoladamente. Esta estratégia tão ampla quanto fragmentada, tão abrangente quanto desconexa, que vem sendo muito utilizada pela publicidade nos últimos anos, é tecnicamente conhecida por cross media.

\section{A estratégia multimeios}

O que foi característico da comunicação publicitária nas últimas décadas, ao menos até o início dos anos 2000, fruto da fragmentação dos meios e do surgimento de tantos outros como a internet, o telefone celular como mídia, a TV e o rádio digital, as redes sociais e os videogames, foi o estabelecimento de uma ação multimeios, de amplo espectro, que visava atingir o maior número possível de consumidores através de toda a mídia disponível. Assim, as empresas e suas agências de publicidade desenvolviam um conceito de comunicação central e esse conceito era replicado - ou campanhado, para se utilizar o termo do jargão publicitário - para todos os meios. Quanto maior o número de meios em que uma comunicação estivesse disponível para o consumidor, a iniciativa possibilitava maiores chances de eficiência. A estratégia de comunicação baseava-se, assim, em uma sequência de procedimentos que começava com a definição de um forte conceito criativo, depois com o mapeamento e compreensão profunda dos consumidores-alvos (normalmente por meio de um programa de gerenciamento das relações entre a marca e seus consumidores, conhecido por CRM - Customer Relationship Management), procedimentos que possibilitavam, em seguida, a definição de quais as mídias mais eficientes para se atingir esses consumidores, para, finalmente, chegar-se à aplicação do conceito para as várias mídias, construindo uma iniciativa de comunicação multimedial e de ampla abrangência. Esta estratégia comunicacional é denominada multimeios.

Um exemplo de comunicação multimeios é a campanha do cartão de crédito VISA, de 2005, na qual o mesmo conceito (e praticamente as mesmas peças publicitárias) é apresentado nas várias mídias, como ilustram as fotos abaixo: 


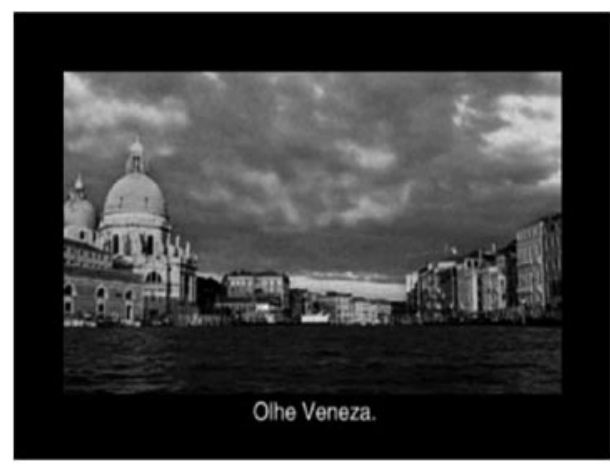

Televisão

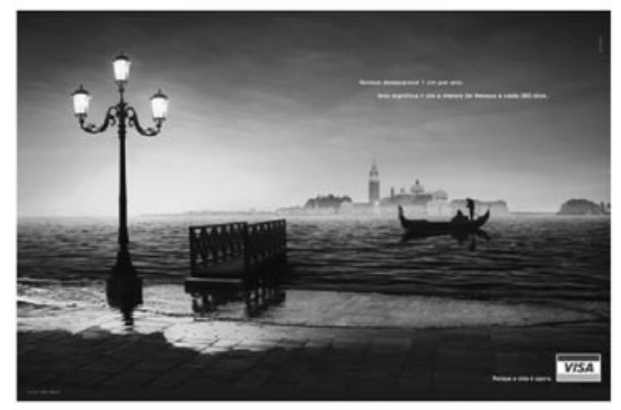

Mídia Impressa

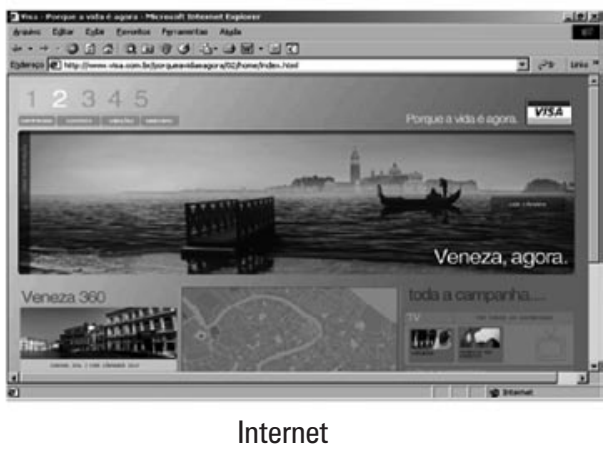

A estratégia de multimeios, de uma forma mais geral, pode ser pensada como uma iniciativa comunicacional que se realiza por meio de uma pluralidade de meios, em uma estratégia unitária e integrada e que frui por mais de um canal sensorial, que convoca sinestesicamente mais de um sentido (COSENZA, 2004 , p. 23). Desta maneira, aproximam-se os multimeios de certa multisensorialidade ou, em construção mais próxima às elaborações do linguista Louis Hjelmslev (1975), de uma multisubstancialidade, isto porque se acentua o fato de que os textos multimeios são baseados em muitas substâncias da expressão, envolvendo muitos canais sensoriais (COSENZA, 2004, p. 21).

Uma abordagem pelo olhar da semiótica sincrética parece dar conta de compreender o fenômeno da comunicação multimeios. De fato, são consideradas sincréticas as semióticas que acionam várias linguagens de manifestação (GREIMAS; COURTÉS, 1983, p. 426), designando textos construídos pela utilização de duas ou mais linguagens de manifestação que interagem, formando um todo de sentido. Desta forma, essas semióticas constituem um todo de significação no plano do conteúdo a partir de elementos do plano da expressão dependentes de várias semióticas ou, mais exatamente, configurariam as semióticas nas quais a forma do conteúdo seria expressa por mais de uma substância da expressão, mas cujo sentido seria produzido pelo mesmo ato de enunciação. 
De fato, na comunicação multimeios, o conceito criativo único (substância do conteúdo), articulado através dos recortes e seleções dos tipos de linguagem (forma do conteúdo), por uma estratégia enunciativa única, é expresso por várias substâncias da expressão (as diversas mídias, através das linguagens verbal, musical, sonora, imagética, gestual, audiovisual etc.), que se organizam pelas várias formas da expressão (notas, formantes eidéticos, cromáticos e topológicos - no visual, cinéticos - no cinema e na TV, pixels e formantes da imagem - na internet etc.).

É claro que, isoladamente, cada uma das peças publicitárias produzidas na comunicação multimeios pode e deve ser analisada, em si, como um texto sincrético. Os spots de TV, as peças de internet, os comercias no cinema, os anúncios nas revistas, todos eles constituem o significado de seus conteúdos pela articulação de uma ou mais linguagens no plano da expressão. No entanto, a estratégia mesma dos multimeios, a colocação no ar de todas as peças publicitárias nas várias mídias, constitui, ela também, uma estratégia sincrética. Conforme nos esclarece Jean-Marie Floch, no dicionário II de Greimas e Courtés (1991, p. 234, verbete "Sincrética - Semióticas"):

"O recurso a uma pluralidade de linguagens de manifestação para construir um texto sincrético depende, cremos, de uma estratégia global de comunicação sincrética que "administra", se se quiser, o contínuo discursivo resultante da textualização e elege "verter" a linearidade do texto em substâncias diferentes; em certos casos, os procedimentos de sincretização podem depender de verdadeiras sinestesias. Esta estratégia sincrética depende da competência discursiva de um só e único enunciador, mesmo quando este se actorializa muito diversamente."

É exatamente o que verificamos na estratégia multimeios: uma única e global estratégia de comunicação sincrética, através de um único enunciador (a marca), coloca em discurso as várias peças publicitárias, nas muitas mídias. Mesmo que por simultâneos - às vezes sucessivos - procedimentos de enunciação, já que cada peça, na sua mídia, vai erigir específicas instâncias enunciativas, um movimento geral e totalizante vai coordenar e integrar as diferentes presenças de marca, através das peças diversas, possibilitando certa linearidade no discurso construído. O consumidor-enunciatário, que por sua vez pode ser exposto a uma ou a várias mídias (a várias peças publicitárias, portanto), mesmo construindo experiências diferentes (a interação na internet certamente é diversa da experimentada na televisão), conseguirá construir sentidos mais uniformes da comunicação, já que se parte de um conceito único, que mesmo expresso por várias linguagens (por várias semióticas), é discursivizado por um fazer enunciativo único, globalizante, integrador.

Ao se falar em estratégia cross media, no entanto, não se tem uma comunicação única, totalitária, que de uma forma abrangente nos apresenta através dos diversos meios e, sendo vista em uma ou em muitas mídias, possibilitará a construção quase que homogênea de sentido - claro que de uma forma muito generalizada, já que se trata da mesma e exata comunicação recortada 
segundo as características e potencialidades do meio em que ela se expressa. Ao invés disso, o cross media constrói conceitos criativos específicos para cada um dos meios, textos publicitários diversos simultaneamente apresentados nas distintas mídias, ao mesmo tempo presentes aos sentidos do consumidorenunciatário. Assim, constroem-se experiências de marca muito diferentes ao possibilitar o encontro do consumidor com uma ou outra mídia, neste ou naquele tempo, em um espaço (na internet, por exemplo) ou em outro (no ponto de vendas).

Entender o cross media pelo olhar da semiótica sincrética é pouco significativo, já que não se tem mais um conteúdo único expresso por várias linguagens. Ao contrário, são várias substâncias do conteúdo (vários conceitos), recortadas por várias formas do conteúdo (fotografias, jogos eletrônicos, toques de celular, filmes publicitários etc.), que se apresentam simultaneamente por várias substâncias e formas da expressão, através de muitos atos enunciativos. Pouco se pode avançar, semioticamente, através de um esforço metodológico puramente sincrético. Como pensar então os recentes movimentos publicitários do cross media aos olhos da semiótica?

\section{A estratégia midiática de cross media}

O cross media nasce, na publicidade e no marketing, a partir da constatação de que o consumidor mudou. Na verdade, de um olhar muito mais profundo do que isso: de que, além do consumidor ter mudado (o que não representa grande surpresa, mas sim, ao contrário, é aspecto bastante óbvio no mundo das comunicações), agora se torna possível mensurar, qualificar, quantificar, mapear e armazenar todas essas mudanças pelas novas abordagens do marketing e das suas pesquisas de mercado. É exatamente em função desse conhecimento mais profundo das relações entre o consumidor e a marca, dele com outros consumidores e consigo mesmo, agora de conhecimento e domínio do marketing, que se estabelecem as iniciativas de cross media.

A questão das mudanças recentes no mundo do consumidor, nos seus comportamentos e nas suas relações sociais, é observada com propriedade pela sociologia do consumo. Fabris (2003, p. 38, tradução e grifo meus) já observara que:

"O consumidor pós-moderno não se caracteriza apenas por dar mais espaço às emoções, ao sensorial; por utilizar o consumo como signo e comunicação da própria identidade; por demonstrar uma maior autonomia do mundo da produção; por interessar-se pelo inédito e pelo diferente; por recorrer, mesmo no processo de compras, à criatividade è ìmaginação. Mesmo o explorar do shopping não se explica - na maioria das vezes - pela busca das soluções mais convenientes, mas se desenvolve, para o novo consumidor flaneur (vagante), sob a égide do jogo e do prazer. Comumente orientado ao lúdico, se esgota propriamente no window shopping entendido como uma intrigante atividade de tempo livre - isto é, no consumir uma experiência - voltada para si mesma, sem qualquer finalidade de compra." 
A construção de experiências significantes de marca é, de fato, o grande elemento motivador da estratégia de cross media. O que o marketing compreendeu, nos últimos anos, é que a experiência construída entre o consumidor e a marca é peculiar e específica para cada uma das mídias, ou seja, que os regimes de sentido que se estabelecem a partir das interações entre consumidor e marca ao assistir uma publicidade na TV são absolutamente diversos daqueles edificados na copresença mesma entre os dois actantes na internet, no ponto de vendas, ao acessar um site mobile pelo celular, ao jogar um videogame no qual a marca se faz presente e assim sucessivamente. Mais do que isso: o que os programas de marketing têm realizado é um mapeamento sistêmico de todas essas experiências estabelecidas pelo consumidor nas suas interações com a marca nas diferentes mídias, construindo mesmo uma "grade de relacionamento" que, segundo uma escala de valores instituída para cada marca, empresa ou indústria, qualifica e estratifica as experiências de marca pelos meios.

É claro que não se requer muita energia metodológica e teórica para se compreender que marca (via discurso publicitário, produto, comunicação institucional, patrocínio etc.) e consumidor, em presença nas diversas mídias, pelas diferentes formas de interação (direta, mediada, virtual etc.), geram diferentes experiências e, por meio delas, portanto, diferentes efeitos de sentido. Também estabelecer uma grade estanque, congelada, do comportamento do consumidor em cada uma das mídias - ou dos sentidos possibilitados pela interação entre marca e consumidor em cada uma delas - criaria no máximo uma semiologia das mídias muito pouco útil para o fazer mercadológico, dado que, como é imediato para a semiótica, um sentido cristalizado, inerte, independente da ação dos sujeitos (ou do sujeito e do objeto), é, no mínimo, um não-sentido.

Assim, mais do que mapear - diremos - o "funcionamento de cada mídia", o que já é bastante conhecido pelas ciências da Comunicação e o que pouco contribuiria para melhorar a efetividade das ações de marca (ou para construir experiências mais sensíveis e significantes para o consumidor), o que o marketing tem feito é compreender que cada uma dessas experiências de marca, em cada um dos meios, entre os actantes em copresença, reconstrói o sentido da experiência mesma, da marca e, especialmente, do próprio sujeito, ou seja, o consumidor se reapresenta, para a marca, a partir dessas experiências em ato. E é isso que interessa mais às marcas: quais são essas várias reapresentações, esses outros e novos sentidos que o consumidor-sujeito se possibilita a partir das várias experiências de marca que as interações em presença nas várias mídias possibilitam.

É nesta perspectiva que se estrutura conceitualmente o cross media. Conceitos diferentes, peças criativas distintas e execuções específicas e exclusivas para cada uma das experiências - para cada uma das mídias, portanto - que se propuser ao consumidor. E, mais do que isto, utilizações da mídia que sejam mais do que puramente publicidade (no jargão da área se fala em advertainment, uma fusão entre advertising e entertainment). Assim, executar uma estratégia de cross media significa realizar campanhas de informação, entretenimento, publi- 
cidade e comunicação pública e institucional de modo "integrado”, utilizando muitas mídias simultaneamente (cada uma com o seu target, as suas especificidades técnicas e a sua linguagem) no interior de um sistema comunicativo único e estruturado (GIOVAGNOLI, 2005, p. 18).

Torna-se também elemento motivador da estruturação de estratégias comunicativas cross midiáticas outro desdobramento das ferramentas de conhecimento, monitoramento e sistematização do consumidor e dos seus hábitos de consumo experimentado pelo Marketing nos últimos anos. Se o consumidor pós-moderno se fragmenta, torna-se muitos consumidores nas suas inúmeras experiências de consumo, assume e negocia identidades múltiplas nas suas complexas interações sociais (reais ou virtuais), tornando-se muitos consumidores num só homem, como já nos mostraram os estudiosos da sociedade pós-moderna, passa a ser também evidente para a comunicação empresarial que haverá distintos estágios - ou distintas relações - provenientes das inúmeras interações entre o consumidor e a marca, o que deve possibilitar também comunicações diferentes para um mesmo consumidor em função do seu "estágio” de relação com a marca.

Assim, para a indústria automobilística, um mapeamento exaustivo das relações e interações que ocorrem entre o consumidor e a marca ao longo do processo de compras permite estruturar uma axiologia da experiência de marca erigida em quatro grandes etapas. Na primeira, que pode ser denominada $\mathrm{Co}-$ nhecimento, o consumidor ainda não se decidiu pela compra do produto, não foi até então seduzido pelas mensagens publicitárias e, portanto, não tem ainda qualquer proximidade com a marca e seus produtos. Nesta etapa, na qual a experiência de compras ainda está por desenhar-se, a comunicação publicitária deve se voltar para a atratividade, para despertar o interesse e a relevância do consumidor para a marca e seus produtos, para a construção do desejo maior de conhecer o segmento (automotivo). Assim, nesta fase inicial, a marca se deixar falar, ser referendada por outros (como jornalistas, blogueiros, especialistas etc.), torna-se mais efetiva do que a tradicional "voz do fabricante" do discurso publicitário convencional - e, portanto, a mídia espontânea, as redes sociais, a imprensa e o boca-a-boca (estimulado ou não) tornam-se muito mais efetivos como meios de comunicação.

Na segunda etapa da experiência de compras o consumidor já teve uma aproximação inicial com as marcas e produtos do mercado e já se sente motivado a conhecer mais e aprofundar relacionamentos: é a etapa de escolha e decisão por uma marca ou produto, em fase denominada Consideração, na qual o consumidor começa a conhecer os benefícios, os valores que cada produto ou marca carrega e constrói, motivado ou seduzido pelas manifestações publicitárias das mídias de massa, das revistas especializadas, dos sites das marcas e da comunicação publicitária on-line em geral.

Se na fase anterior operavam os processos clássicos da manipulação publici- 
tária, na tentativa de evidenciar e trazer os olhares e interesse do consumidor para essa ou aquela marca, na etapa seguinte, a do Engajamento, é quando efetivamente o consumidor opta por uma marca ou produto e, para tal escolha, precisa recolher todas as informações necessárias para a tomada de decisão. Assim, uma comunicação mais informativa é muito mais eficiente, tais como as malas-diretas personalizadas, os anúncios de jornal e revista que explicitam e demonstram mais os produtos e seus features, os hot sites de produto com toda a sua riqueza de informação e mesmo o ponto de vendas, onde o consumidor é convidado a conhecer fisicamente o produto.

Por fim, na etapa final, a da Conversão, é quando, após a experimentação do produto e a obtenção das informações finais e decisivas para o processo de compras (preço, condições de pagamento, taxa de juros, disponibilidade de financiamento etc.), o consumidor decide (ou não) pela aquisição do veículo e encerra a experiência de compras, possivelmente iniciando a experiência de pós-vendas e de serviços, que também apresenta a sua segmentação.

Como se vê, já que o mesmo consumidor se apresenta diferentemente em cada uma das etapas de relacionamento com a marca, na construção da sua experiência de compras - etapas essas conhecidas, mapeadas e acompanhadas pelos departamentos de marketing das empresas -, da mesma forma que para cada uma dessas etapas alguns meios e mensagens são mais efetivos e eficientes, perfeitamente, percebe-se que discursos publicitários, também específicos, são mais coerentes para cada uma dessas etapas do programa de relacionamento entre consumidor e marca. Esta é a essência do cross media que estrutura comunicações diferentes, específicas e determinadas para cada tipo de relação que o consumidor estabelece com a marca nas suas experiências de marca. Isso justifica, do ponto de vista mercadológico, peças e conceitos comunicativos diferentes sendo veiculados simultaneamente em uma mesma campanha publicitária, em mídias diferentes, como prenuncia a estratégia publicitária cross midiática. O quadro abaixo resume as fases do processo de construção da experiência de compras no mercado automotivo:

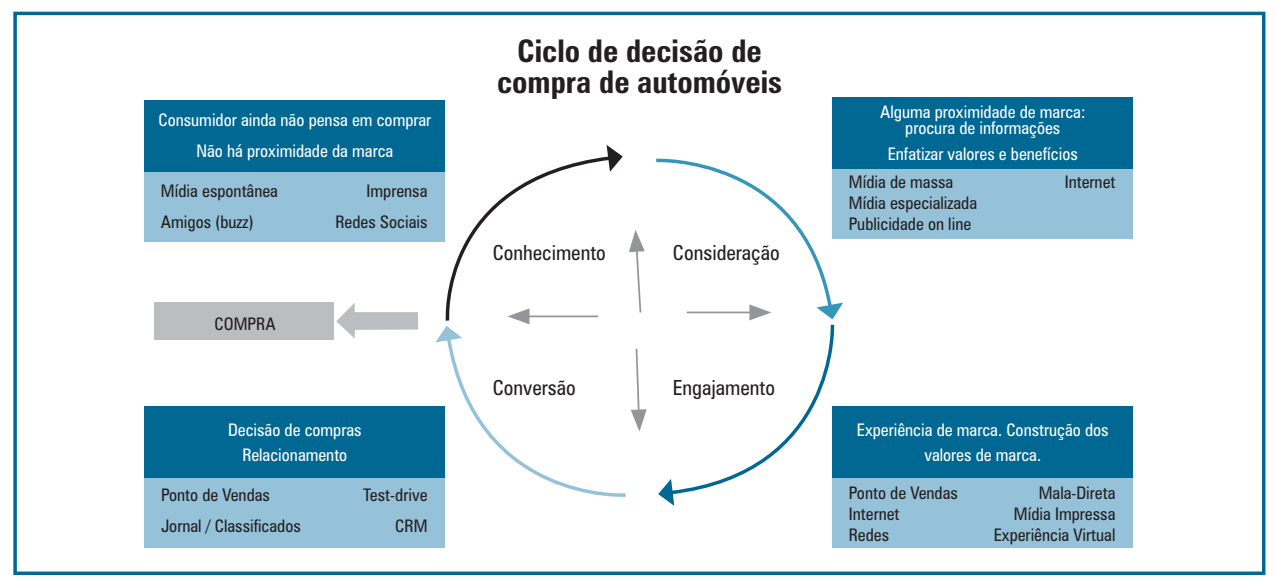


Se o cross media se justifica mercadologicamente, como apresentado anteriormente, do ponto de vista conceitual, aos olhares da semiótica, como ele pode ser estruturado? Como já discutido, uma abordagem pela semiótica sincrética parece não dar conta de explicitá-lo e a direção metodológica caminha na direção da experiência de marca. Mas qual é esse estatuto semiótico que a experiência pode trazer ao estudo da estratégica de cross media?

\section{Uma abordagem semiótica do cross media}

Ana Cláudia Oliveira, ao estudar as relações entre a comunicação e a produção de sentido (2009, p. 5), começa a desvelar um caminho teórico para a abordagem da problemática do cross media. A semioticista explicita que:

"Se o alvo da análise semiótica é o sentido da vida, dos que a vivem e de suas formas de vivê-la nas mutabilidades que as estão constituindo e imprimindolhes qualidades e qualificações que lhe atribuem um modo de presença sensivel do mundo e, em suas reiterações, um estilo e uma identidade, a semiótica está além dos textos de papel (os da midia impressa, por exemplo), dos das ondas (do rádio, da televisão, da internet), dos da luz (os da fotografia, da pintura) $e$ ocupa-se igualmente da tessitura das práticas sociais, que são vividas ou estão sendo, no fluxo de suas ações e do desenrolar de seus programas narrativos, patêmicos, figurativos, enunciativos."

Assim, a partir daí, podemos pensar em dois níveis - ou em dois tempos para a compreensão dos sentidos da comunicação: o primeiro discursivo, o da narração possibilitado pelas mídias e, o segundo, o vivido, o da experiência promovida pelas práticas sociais motivadas pelas tantas experiências de marca. O tempo discursivo, enunciado no e pelos textos, já é ampla e profundamente tratado pela teoria semiótica - e satisfatoriamente dá conta da publicidade multimeios em suas variadas manifestações textuais (comerciais de TV, spots de rádio, anúncios de mídia impressa, banners e sites na internet e tantos outros textos). No entanto, estudar semioticamente uma estratégia cross midiática, nas suas múltiplas relações entre a marca e seus consumidores, requer ir além do trabalho sobre os textos produzidos por ela e, principalmente, tentar compreender a organização e os efeitos de sentido das práticas em curso sob o olhar das diversas partes envolvidas na comunicação.

Mais do que uma abordagem teórica, o que esses dois modos semióticos de compreensão das estratégias comunicativas pressupõem, o que esses dois matizes subsumem, são duas relações bastante diversas entre enunciador e enunciatário, entre marca e consumidor, entre sujeito e objeto (LANDOWSKI, 2004, p. 15-37). Ao tratar as manifestações multimeios como textos, numa enunciação sincrética, objetiva-se a iniciativa comunicacional - e o outro, portanto - erigindo um olhar instrumental e operacional do mundo. A construção dos valores (e dos sentidos) se dá pela marca unilateralmente, apenas a partir do seu ponto de vista e dos seus próprios programas (narrativos e comu- 
nicacionais), cujos consumidores-enunciatários e seus comportamentos, frutos dos procedimentos mercadológicos de segmentação, já são previamente conhecidos, mapeados e esperados. O modelo semiótico clássico de "junção", da gramática narrativa greimasiana, é bastante eficaz para tratar esse regime de interação, como já discutido anteriormente.

Mas também é possível se pensar numa outra relação entre marca e consumidor que não passe pela instrumentalização e operacionalização de um pelo outro, como nos esclarece Landowski (2004, p. 27-28), mas sim numa forma de ajustamento entre suas intenções, projetos, provocações, construção e manifestação identitárias, ajustamento esse que descortina outro estatuto do sentido, que:

“(...) por sua construção, não seria mais integral e unilateralmente fixado de antemão em função exclusivamente dos critérios de pertinência utilizados pelo sujeito de referência, mas cuja emergência seria tornada inseparável da construção recíproca dos dois parceiros em relação, na qual aquele que toma o papel de 'sujeito' só pode completar a si mesmo condicionalmente, por meio da complementação simultânea do outro, daquele que se diz 'objeto'."

É o que parece melhor explicitar as relações estabelecidas pela estratégia de cross media: a marca se apresenta de uma forma menos totalizante, já que reconhece que seu consumidor não é uno, é mutável, se manifesta, se identifica e se reapresenta apenas nas relações e experiências estabelecidas em copresença (real ou não), no instante mesmo da interação em ato. Da mesma maneira, a marca não dirige unilateralmente a comunicação, já que cabe ao consumidor eleger as comunicações com as quais ele - e apenas ele - irá interagir. A iniciativa cross midiática deixa de ser objetivante por se preocupar menos em construir peças publicitárias (textos) que reflitam conteúdos e sentidos definidos e muito mais por buscar práticas que permitam fazer-ser o sentido a partir da construção recíproca e ajustada entre consumidor e marca. A marca, apesar de motivadora, pode inclusive deixar de estruturar e "manipular" a comunicação, se deixando falar, comentar, experienciar pelos seus consumidores.

Mas é evidente que a estratégia de cross media, dentro das interações de ajustamento do modelo semiótico das práticas sociais, não pressupõe uma atitude mais altruísta e desinteressada do que qualquer outra iniciativa publicitária ou mercadológica. Os objetivos e direcionamentos empresariais que regem o fazer da marca permanecem e a intenção final de manipulação que possibilite a realização do contrato (a venda do produto anunciado, em última instância) continua evidente. O que ocorre é que os programas que regem as interações (presentes e até futuras) entre todos os actantes do processo comunicacional - mais exatamente entre a marca e seus múltiplos consumidores - estabelecem-se em um nível diverso, possivelmente mais coerente com os caminhos e práticas que se desenham na atual sociedade de consumo. $\mathrm{Na}$ verdade, as empresas, as marcas, as pessoas, todos nós, buscamos efetivamente relações criadoras de sentido e valor - afinal, é isto que torna o mundo significativo, 
que nos faz sujeitos presentes no mundo - e, para tanto, é fundamental compreender as dinâmicas que possibilitem as "interações sensíveis". É isso o que a publicidade cross media faz.

\section{Conclusões: alguns caminhos}

Apesar do cross media ser hoje a estratégia comunicativa dominante nos departamentos de marketing das empresas e nas suas agências de publicidade, a comunicação multimeios também continua sendo empregada em alguns segmentos e mercados. Não há estratégia melhor ou pior, mais ou menos eficiente; as duas podem trazer efetividade dependendo do produto e da adequação e maturidade do mercado consumidor do segmento em que a empresa atua, bem como da própria cultura interna da organização.

Não se pretendeu aqui avaliar essa efetividade de uma ou outra estratégia publicitária, mas sim buscar, pelo olhar da semiótica, caminhos teóricos para se compreender uma e outra iniciativa. A estratégia multimeios pode ser analisada com precisão pelos procedimentos da semiótica sincrética e pelo regime de junção da gramática narrativa clássica, pensando-se em textos (também sincréticos, individualmente) e em uma enunciação sincrética englobante. Obviamente tal procedimento implica num direcionamento mais unilateral da marca em direção a seus consumidores, uma vez que se pretende certo controle sobre os sentidos que os textos carregam e constroem.

Já o cross media parece ser compreendido pela semiótica somente enquanto uma prática social - e não mais como um conjunto de textos orquestrados sincreticamente. E, como tal, só possibilita a construção de sentido nas relações de ajustamento em interações de copresença entre a marca e seus consumidores. É da relação, da experiência, do ato mesmo de interação que a marca (e mesmo o consumidor) constrói e reconstrói o seu sentido e seus valores.

Temos visto, não tão-somente por um viés semiótico, que as marcas têm ultrapassado as fronteiras da comunicação publicitária, possibilitando a construção de experiências a serem vividas, discutidas, narradas, compartilhadas, lembradas. As marcas passam mesmo a transmitir e construir ideias, ideais e até a reafirmação da identidade de quem as adota e consome. Desta maneira, as empresas mais e mais perdem o controle rígido sobre a construção, propagação e valoração de suas marcas. Com o cross media - sem se saber exatamente se ele é reflexo ou motivador de tal movimento - as marcas passam a assumir um estatuto diferente, passam a ser abertas, dadas à interpretação.

Fala-se hoje, nos processos de construção de marcas, em open source branding, que é exatamente a estruturação de um processo colaborativo, por meio das várias iniciativas de comunicação e dos tantos meios, como blogs, microblo- 
gs, comunidades, mídias sociais etc., que possibilitará a construção, posicionamento e valorização das marcas no mundo cross midiático. Certamente, isso vai requerer um novo olhar sobre as marcas e seus programas de branding, bem como assumir que a imagem de marca - o seu sentido, sua identidade - vai muito além do conteúdo oficial que a empresa e suas campanhas publicitárias gostariam de assegurar.

Mas, de qualquer forma, como bem nos ensina a semiótica, o sentido não pode ser algo escondido a se "revelar", a se materializar aos nossos olhos, liberado das codificações das mensagens. O sentido precisa ser sempre e invariavelmente construído e construído na interação entre um sujeito e um objeto, entre dois ou mais sujeitos (ou objetos), entre um eu e um outro, entre uma marca e seus consumidores. Como nos lembra sempre Landowski (2004, p. 26), "fazer-ser o sentido constitui, assim, uma exigência primeira em relação a nós mesmos: é a condição fundamental da nossa completude".

\section{Referências}

BARROS, D.L.P. Teoria do Discurso: fundamentos semióticos. São Paulo: Humanitas / FFLCH / USP, 2001.

COSENZA, G. Semiotica dei nuovi media. Roma: Editori Laterza, 2004.

FABRIS, G. II nuovo consumatore: verso il postmoderno. Milano: FrancoAngeli, 2003.

GIOVAGNOLI, M. Fare cross-media. Roma: Dino Audino Editore, 2005.

GREIMAS, A. J.; CORTÉS, J. Dicionário de Semiótica. São Paulo: Cultrix. 1983. . Semiotica. Diccionario razonado de la teoria del lenguaje. Tomo II. Madrid: Editorial Gredos, 1991.

HJELMSLEV, L. Prolegômenos a uma teoria da linguagem. São Paulo: Perspectiva, 1975.

LANDOWSKI, E. Le regard implique. In: Passions sans nom. Essais de socio-sémiotique III. Paris: Presses Universitaires de France, 2004. p. 13-37. . Unità del senso, pluralità di regimi. In: MARRONE, G.; DUSI, N.; FREDO, G. Narrazione ed experienza: intorno a una semiótica della vita quotidiana. Rome: Meltemi Editore, 2007. p. 27-43.

OLIVEIRA, A.C. Comunicação e produção semiótica de sentido. São Paulo, 2009. Mimeografado. 